\title{
BIBLIOGRAFIA PRAC NAUKOWYCH PROFESOR BARBARY CZOPEK-KOPCIUCH ${ }^{1}$ [BIBLIOGRAPHY OF THE WORKS OF PROFESSOR BARBARA CZOPEK-KOPCIUCH]
}

Przymiotniki na -alny, -arny w historii języka polskiego na tle słowiańskim [Adjectives in -alny and -arny in the history of Polish against a general Slavic background]. Polonica, 4, 203-214.

[spraw.] XIII Międzynarodowy Kongres Onomastyczny (Kraków, 21-25 VIII 1978). Poradnik Językowy, 2, 92-95.

[rec.] M. Brzezinowa, Języki mniejszości narodowych w tekstach literackich i folklorystycznych. I. Południowokresowa polszczyzna Żydów, Warszawa-Kraków 1979, 152 s., Język Polski, 61, 128-132.

[rec.] Vostočno-slavânskaâ onomastika. Issledovaniâ i materialy, red. S. Rospond, W.E. Staltmane, A.V. Superanskaâ i in., cz. 2, Moskva 1979, 350 s., Onomastica, 26, 270-277.

[rec.] I. Nowakowska-Kempna, Transpozycje nazw własnych z języka polskiego na języki południowosłowiańskie, Katowice 1979, 197 s., Onomastica, 27, 308-314.

1984

Apelatyw majdan w toponimii polskiej [The appellative majdan in Polish toponymy]. Onomastica, 29, 69-89. \footnotetext{
Czopek, od roku 1995 używała nazwiska dwuczłonowego.

1 Profesor Barbara Czopek-Kopciuch pierwsze prace opublikowała pod panieńskim nazwiskiem 
The Ukrainian influences in the place names along the border of the eastern part of

Poland. W: I. Bily i in. (red.), Resümees der Vorträge und Mitteilungen. XV. Internationaler Kongress für Namenforschung, Karl-Marx-Universität Leipzig, 13.-17. August 1984 (s. 41). Leipzig: Karl-Marx-Universität.

\section{5}

Ajkonimy adgidranimičnaga pahodžannâ basejna Buga na terytoryi perahodnyh gavorak: polska-ukrainskih i polska-belaruskih [Oikonyms of hydronymic origin of the Bug Basin in the area of the transitional dialects: Polish-Ukrainian and Polish-Belarusian]. Belaruskaja anamastyka, 3, 81-86.

The Ukrainian influences in the place names along the border of the eastern part of Poland. W: E. Eichler, E. Sass i W. Walther (red.), Der Eigenname in Sprache und Gesellschaft. XV. Internationaler Kongress für Namenforschung 13.-17. August 1984 (s. 25-31; mikrofilm). Leipzig: Karl-Marx-Universität.

\section{6}

Ukraińskie cechy językowe w nazwach miejscowych dawnej ziemi chełmskiej i bełskiej [Ukrainian language features in the place names of the former Chełm and Bełz land]. W: S. Warchoł (red.), Formacje hybrydalne w językach stowiańskich [Hybrid Formations in Slavic Languages] (s. 137-144). Lublin: Wydawnictwo UMCS. [spraw.] Konferencja: Formacje hybrydalne w językach słowiańskich (Lublin 10-11 maja 1984). Onomastica, 31, 295-298.

\section{8}

Nazwy miejscowe dawnej ziemi chetmskiej i betskiej (w granicach dzisiejszego państwa polskiego) [Place Names of the Former Chełm and Bełz Land (Within the Borders of Present-Day Poland)]. Wrocław: Zakład Narodowy im. Ossolińskich. Rec. Janeczek, A. (1991(1992)). Onomastica, 36, 247-258.

[rec.] A.V. Superanskaâ, Čto takoe toponimika?, Moskva 1985, 176 s., Onomastica, 32, 201-205.

1989

[rec.]. E. Eggers, Die Phonologie der deutschen Lehnwörter im Altpolnischen bis 1500, München 1988, 221 s., Polonica, 54, 215-220.

[rec.] Etimologičnij slovnik litopisnih geografičnih nazv Pìvdennoï Rusì, oprac. İ.M. Želêznâk, A.P. Korepanova, L.T. Masenko i O.S. Strižak, Kiïv 1985, 253 s., Onomastica, 33, 274-278. 
[z E. Rymarem] Nazwy młynów i osad młyńskich na terenie dawnej Nowej Marchii [Names of mills and mill settlements in the area of the former New March]. Onomastica Slavogermanica, 18, 61-115.

Personennamen in den Ortsnamen deutscher Herkunft auf dem Gebiet Polens. W: D. Kremer (red.), Onomastik. Akten des 18. Internationaler Kongress für Namenforschung (Trier 12.-17. April 1993) (s. 32-33). Tübingen: Max Niemeyer Verlag.

[rec.] E. Rzetelska-Feleszko i J. Duma, Dawne słowiańskie nazwy miejscowe Pomorza Szczecińskiego, Warszawa 1991, 300 s., 16 map, Onomastica, 38, 273-275.

[rec.] S. Körner, Ortsnamenbuch der Niederlausitz. Studien zur Toponymie der Kreise Beeskow, Calau, Cottbus, Eisenhüttenstadt, Finsterwalde, Forst, Guben, Lübben, Lucka und Spremberg. Sächsische Akademie der Wissenschaften zu Leipzig. Deutsch-slawische Forschungen zur Namenkunde und Siedlungsgeschichte, t. 36, Berlin 1993, 296 s., mapa, Onomastica, 39, 237-242.

[spraw.] XVIII Międzynarodowy Kongres Onomastyczny (Trewir, 12-17 IV 1993). Onomastica, 39, 275-282.

1995

Adaptacje niemieckich nazw miejscowych w języku polskim [Adaptations of German Place Names in Polish]. Kraków: Instytut Języka Polskiego PAN. Rec. Biolik, M. (1997). Onomastica, 42, 279-290; Kowalczyk, E. (1997). KHKM, 45, 229-236.

Das frühmittelalterliche Krakow als städtisches Zentrum der Fürstenmacht — im Lichte der Ortsnamen. W: H.J. Brachmann (red.), Burg - Burgstadt - Stadt. Zur Genese mittelalterlicher nichtagrarischer Zentren in Ostmitteleuropa (s. 176182). Berlin: Akademie Verlag.

[rec.] Burg — Burgstadt — Stadt. Zur Genese mittelalterlicher nichtagrarischer Zentren in Ostmitteleuropa, red. H.J. Brachmann, Berlin 1995, 348 s., Onomastica, 40, 224-227.

[rec.] C. Willich, Die Ortsnamen des Landes Lebus, mit einem siedlungsgeschichtliches Beitrag von R. Barthel. Brandenburgisches Namenbuch, t. 9, Weimar 1994, 319 s., 8 map, Onomastica, 40, 227-230.

1996

[z E. Rymarem] Anojkonimy na terenie dawnej Nowej Marchii [Anoikonyms in the area of the former New March]. Onomastica Slavogermanica, 20, 13-100. 
Badania onomastyczne w Polsce (1990-1996) [Onomastic research in Poland (19901996)]. Acta onomastica, 37, 36-46.

Nazwy miejscowe Polski [Place names of Poland]. Działalność naukowa PAN. Wybrane zagadnienia, s. 17.

[autorka części haseł] K. Rymut (red.). Nazwy miejscowe Polski. Historia. Pochodzenie. Zmiany [Place Names of Poland. History. Origin. Changes] (t. I: A-B). Kraków: Instytut Języka Polskiego PAN.

„Prymarność”, „sekundarność”, „równość” w toponomastyce [,Primarity”, „,secondarity”, ,equality” in toponomastics]. Sprawozdania z Posiedzeń Komisji Naukowych Oddziału PAN, 40(1), s. 13.

1997

[autorka części haseł] K. Rymut (red.). Nazwy miejscowe Polski. Historia. Pochodzenie. Zmiany [Place Names of Poland. History. Origin. Changes] (t. II: C-D). Kraków: Instytut Języka Polskiego PAN.

Przynależność językowa dawnej Nowej Marchii w świetle danych toponomastyki [Linguistic status of the former New March in the light of toponymic data]. W: H. Popowska-Taborska i J. Duma (red.), Onomastyka i dialektologia. Prace dedykowane Pani Profesor Ewie Rzetelskiej-Feleszko [Onomastics and Dialectology. Works Dedicated to Professor Ewa Rzetelska-Feleszko] (s. 55-64). Warszawa: Slawistyczny Ośrodek Wydawniczy.

\section{8}

Onymische Integration in Untersuchungen von Ortsnamen. W: W.F.H. Nicolaisen (red.), Proceedings of the XIX International Congress of Onomastic Sciences, Aberdeen, August 4-11, 1996 (cz. 2, s. 66-72). Aberdeen: Department of English University of Aberdeen.

[z J. Dumą] Zum Verhältnis von Orts- und Gewässernamen im Gebiet um Stettin. Onomastica Slavogermanica, 23, 239-252, 3 mapki.

[rec.] E. Foster, Die Ortsnamen des Landes Ruppin. Brandenburgisches Namenbuch, cz. 11, Weimer 1998, 258 s., Onomastica, 43, 366-370.

[rec.] T. Pluskota, Nazwy miejscowe ziem ruskich Rzeczypospolitej XVI i XVIII w. Toponimia Ukrainy i pogranicza polsko-ukraińskiego, Bydgoszcz 1998, 381 s., 10 map, Onomastica, 43, 351-354.

[spraw., z E. Nowak] Sprawozdanie z konferencji: Werkzeug Sprache (Język jako narzędzie), Lipsk 22-23 stycznia 1998. Polonica, 19, 231.

Jeszcze o nazwach miejscowych na -owy [Place names ending with -owy revisited]. Studia i Materiały Polonistyczne, 4, 271-276. 
[autorka części haseł] Rymut, K. (red.). Nazwy miejscowe Polski. Historia. Pochodzenie. Zmiany [Place Names of Poland. History. Origin. Changes] (t. III: E-I). Kraków: Instytut Języka Polskiego PAN.

Ortsnamen auf -burg in slavischen Ländern. W: E. Eggers, J. Becker, J. Udolph i D. Weber (red.), Florilegium Linguisticum. Festschrift für Wolfgang P. Schmid zum 70. Geburtstag (s. 55-62). Frankfurt am Main-Berlin-Bern-Bruxelles-New York-Wien: Peter Lang GmbH, Internationaler Verlag der Wissenschaften.

Personennamen in den Ortsnamen deutscher Herkunft auf dem Gebiet Polens. W: D. Kremer i T. Andersson (red.), Akten des 18. Internationalen Kongress für Namenforschung, Trier, 12.-17. April 1993, t. IV: Personennamen und Ortsnamen. (= Patronymica Romanica, 17) (s. 311-319). Tübingen: Max Niemeyer Verlag. [spraw.] XX Międzynarodowy Kongres Onomastyczny. Onomastica, 44, 199-204.

Elementy niemieckie w nazewnictwie miejscowym Polski południowo-wschodniej [German elements in the place names of south-eastern Poland]. W: E. Wolnicz-Pawłowska i W. Szulowska (red.), Kontakty językowe polszczyzny na pograniczu wschodnim. Prace ofiarowane Profesorowi Januszowi Riegerowi [Linguistic Contacts of the Polish Language on the Eastern Border. Studies Donated to Professor Janusz Rieger] (s. 47-51). Warszawa: Semper.

Profesor Marian Jurkowski jako onomasta i historyk języka [Professor Marian Jurkowski as an onomastician and language historian]. W: B. Czopek-Kopciuch (red.), Język - człowiek - kultura. Księga pamiątkowa poświęcona profesorowi Marianowi Jurkowskiemu [Language — Human — Culture. A Commemorative Book Dedicated to Professor Marian Jurkowski] (s. 305-307). Piotrków Trybunalski: Naukowe Wydawnictwo Piotrkowskie przy Filii Akademii Świętokrzyskiej.

[red.] Język - człowiek — kultura. Księga pamiatkowa poświęcona profesorowi Marianowi Jurkowskiemu [Language - Human - Culture. A Commemorative Book Dedicated to Professor Marian Jurkowski]. Piotrków Trybunalski: Naukowe Wydawnictwo Piotrkowskie przy Filii Akademii Świętokrzyskiej.

\section{1}

[autorka części haseł] K. Rymut (red.). Nazwy miejscowe Polski. Historia. Pochodzenie. Zmiany [Place Names of Poland. History. Origin. Changes] (t. IV: J-Kn). Kraków: Instytut Języka Polskiego PAN.

[z U. Bijak] Nazwy miejscowe Polski. Historia. Pochodzenie. Zmiany [Place Names of Poland. History. Origin. Changes] [w cyklu: Krakowskie Warsztaty Leksykograficzne]. Sprawozdania z Posiedzeń Komisji Naukowych Oddziału PAN, 45(1), 33-34. 
Tuchanie, Uchanie — nazwy miejscowe dzierżawcze czy rodowe? [Tuchanie, Uchanie — possessive or ancestral place names?]. W: A. Cieślikowa i B. Czopek-Kopciuch (red.), Toponimia i oronimia [Toponymy and Oronymy] (s. 113-123). Kraków: Wydawnictwo Naukowe DWN.

[red., z A. Cieślikową] Toponimia i oronimia [Toponymy and Oronymy]. Kraków: Wydawnictwo Naukowe DWN.

[rec.] Historisches Ortsnamenbuch von Sachsen, red. E. Eichler, H. Walther i in., t. I-III, Berlin 2001, 634 s. + 645 s. + 397 s., Onomastica, 46, 363-365.

2002

Fremde Ortsnamen im polnischen Text. W: A. I. Boullón Agrelo (red.), Actas XX Congreso Internacional de Ciencias Onomásticas, Santiago de Compostela, 20-25 de setembro de 1999 (t. 1, s. 821-828). Coruña: Fundación Pedro Barrié de la Maza.

[z A. Cieślikową, K. Skowronek i E. Supranowicz] Mały słownik odmiany nazw własnych [A Small Dictionary of the Inflection of Proper Names]. Kraków: Instytut Języka Polskiego PAN.

Polnische Namen in Deutschland (am Beispiel des Ruhrgebiets). W: E. Brylla i M. Wahlberg (red.), $21^{\text {st }}$ International Congress of Onomastic Sciences. Uppsala 19-24 August 2002. Abstracts (s. 26). Uppsala: Språk- och folkminnesinstitutet.

[spraw.] Konferencja w Wittenberdze (Lutherstadt Wittenberg, 24-27 października 2002). Onomastica, 47, 277-280.

[spraw.] VIII Konferencja ONZ poświęcona standaryzacji nazw geograficznych (Berlin, 27 sierpnia-5 września 2002). Onomastica, 47, 273-277.

[spraw.] XXI Międzynarodowy Kongres Onomastyczny (Uppsala, 19-24 sierpnia 2002). Onomastica, 47, 260-266.

2003

[autorka części haseł] K. Rymut (red.). Nazwy miejscowe Polski. Historia. Pochodzenie. Zmiany [Place Names of Poland. History. Origin. Changes] (t: V: Ko-Ky). Kraków: Instytut Języka Polskiego PAN.

[rec.] G. Holzer, Die Slaven im Erlaftal. Eine Namenlandschaft in Niederösterreich, Wien 2001, 155 s. Rocznik Slawistyczny, 53, 156-161.

Holländische Siedlungsbewegung und Ortsnamen Holendry in Polen. W: D. Stellmacher (red.), Sprachkontakte, Niederländisch, Deutsch und Slawisch östlich von Elbe und Saale. Wittenberger Beiträge zur deutschen Sprache und Kultur (t. 3, s. 323-336). Frankfurt am Main-Berlin-Bern-Bruxelles-New York-OxfordWien: Peter Lang GmbH, Internationaler Verlag der Wissenschaften.

Namen der Länder und Nationalitäten. Geschichte und Gegenwart (Bemerkungen über Wortbildungsstruktur). W: E. Eichler, H. Tiefenbach i J. Udolph (red.), 
Völkernamen - Ländernamen — Landschaftsnamen. Onomastica Lipsiensia. Leipziger Untersuchungen zur Namenforschung (t. 2, s. 129-138). Leipzig: Leipziger Universitätsverlag.

Nazwiska polskie w Zagłębiu Ruhry [Polish Surnames in the Ruhr Region]. Kraków: Instytut Języka Polskiego PAN.

Nick — nowa kategoria antroponimiczna? [Internet nickname — a new anthroponymic category?]. W: K. Michalewski (red.), Współczesne odmiany języka narodowego [Contemporary Varieties of the National Language] (s. 106-111). Łódź: Wydawnictwo UŁ.

Nazwiska polskie w Zagłębiu Ruhry a nazwiska w Polsce [Polish surnames in the Ruhr Region and surnames in Poland]. Onomastica, 50, 243-254.

[autorka części haseł] K. Rymut (red.). Nazwy miejscowe Polski. Historia. Pochodzenie. Zmiany [Place Names of Poland. History. Origin. Changes] (t. VI: La-Ma). Kraków: Instytut Języka Polskiego PAN.

Stanisław Frycie okiem językoznawcy widziany [Stanisław Frycie as seen by a linguist]. W: A. Grochulska (red.), W kręgu literatury i języka [Essays on Literature and Language] (s. 15-20). Piotrków Trybunalski: Naukowe Wydawnictwo Piotrkowskie przy Filii Akademii Świętokrzyskiej.

2006

[autorka części haseł] K. Rymut i J. Hoffman (red.). Lexikon der Familiennamen polnischer Herkunft im Ruhrgebiet (t. 1: A-L). Kraków: Instytut Języka Polskiego PAN.

Nazwiska od przezwisk dwuczłonowych w Zagłębiu Ruhry [Surnames from two-word nicknames in the Ruhr Region]. W: K. Rymut i in. (red.), Munuscula linguistica in honorem Alexandrae Cieślikowa oblata (s. 143-156). Kraków: Instytut Języka Polskiego PAN.

O Nawrockim, Nawrocie i nawrocie [On the surnames Nawrocki, Nawrot and the appellative nawrot]. W: S. Frycie (red.), W'siecie humanistycznych wartości. Rozprawy $i$ artykuły o języku, literaturze i humanistycznych pasjach historyka literatury i badacza kultury — profesora Witolda Nawrockiego. Prace dedykowane profesorowi przez wspótpracowników, przyjaciót i uczniów z okazji 70. rocznicy urodzin i 40. rocznicy działalności naukowej i dydaktycznej [In the World of Humanistic Values. Dissertations and Articles about the Language, Literature and Humanistic Passions of a Literary Historian and Researcher of Culture Professor Witold Nawrocki. Papers Dedicated to the Professor by Colleagues, Friends and Students on the Occasion of the $70^{\text {th }}$ Birthday and $40^{\text {th }}$ Anniversary of his Scientific and Didactic Activity] (s. 11-32). Piotrków Trybunalski: Naukowe Wydawnictwo Piotrkowskie przy Filii Akademii Świętokrzyskiej. 
[z A. Cieślikową The old and the new in onomastic studies. The Polish experience. Onoma, 41, 271-294.

[red., z K. Rymutem, M. Malec i K. Skowronek] Munuscula linguistica in honorem Alexandrae Cieślikowa oblata. Kraków: Instytut Języka Polskiego PAN.

[rec.] S. Frycie, M. Jurkowski, K. Sicińska, Kultura języka polskiego, Warszawa 2005, 273 s., Nowa Szkoła, 66, 55-56.

[rec.] A. Greule, Etymologische Studien zu geographischen Namen in Europa. Ausgewälte Beiträge 1998-2000, red. W. Janka i M. Prinz, Regensburger Studien zur Namenforschung, 2, Regensburg 2007, 264 s., Onomastica, 51, 301-303.

[rec.] Große Flüsse auf dem Gebiet der Bundesrepublik Deutschland. Supplementband zur Reihe „Hydronymia Germaniae”, red. W.P. Schmid i U. Borchers, Stuttgart 2006, 89 s. + mapa. Onomastica, 51, 309-311.

[rec.] Namenforschung morgen. Ideen, Perspektiven, Visionen, red. A. Brendler i S. Brendler, Hamburg 2003, 217 s. Onomastica, 51, 319-322.

[rec.] Namenkundliche Informationen. Beiheft 23: Festschrift zu Ehren von Prof. Dr. Ernst Eichler, red. K. Hengst i D. Krüger, Leipzig 2005, 113 s., Onomastica, 51, 298-301.

[z A. Cieślikową i K. Rymutem] Das polnische Personennamensystem. W: A. Brendler i S. Brendler (red.), Europäische Personennamensysteme. Ein Handbuch von Abasisch bis Zentrallladinisch. Anlässlich der 65. Geburtstage von Rosa Kohlheim und Volker Kohlheim (s. 587-596). Hamburg: Baar-Verlag.

[z U. Bijak] Imiona w nazwach jezior i stawów w Polsce [Personal names in the names of Polish lakes and ponds]. Jezikoslovni Zapiski, 13(1-2), 59-68.

[autorka części haseł] K. Rymut (red.). Nazwy miejscowe Polski. Historia. Pochodzenie. Zmiany [Place Names of Poland. History. Origin. Changes] (t. VII: Mą-N). Kraków: Instytut Języka Polskiego PAN.

Polnische Namen in Deutschland (am Beispiel des Ruhrgebiets). W: E. Brylla, M. Wahlberg i R. Rentenaar (red.), Proceedings of the 21st International Congress of Onomastic Sciences, Uppsala, 19-24 August 2002 (cz. 3, s. 82-88). Uppsala: Språk- och folkminnesinstitutet.

[red., z A. Cieślikową i K. Skowronek] Nowe nazwy własne - nowe tendencje badawcze [New Proper Names - New Research Tendencies]. Kraków: Pandit.

[rec.] M. Biolik, Gewässernamen im Flussgebiet der Narew von der Quelle bis zur Einmündung der Biebrza. Teil II: Die stehenden Gewässer / Nazwy wodne dorzecza Narwi od źródeł do ujścia Biebrzy. Cz. II: Nazwy wód stojących, Stuttgart 2005, 222 s. Onomastica Slavogermanica, 26, 147-149.

[rec.] Europäische Personennamensysteme. Ein Handbuch von Abasisch bis Zentralladinisch, red. A. Brendler i S. Brendler, Hamburg 2007, 863 s., Onomastica, 52, 319-324. 
[rec.] E. Foster, C. Willich, Ortsnamen und Siedlungsentwicklung. Das nördliche Mecklenburg im Früh- und Hochmittelallter. Mit einem siedlungsgeschichtlichen Beitrag von T. Kempke, Stuttgart 2007, 530 s., Onomastica, 52, 338-342.

[spraw., z R. Šrámkiem] Namen als Konfliktpotential im europäischen Kontext (Ratyzbona, 11-13 kwietnia 2007). Onomastica, 52, 408-413.

\section{8}

Imiona ludzi o nazwiskach polskiego pochodzenia na przykładzie mieszkańców Herne w Zagłębiu Ruhry [Given names of people with surnames of Polish origin among the inhabitants of Herne in the Ruhr Region]. W: E. Laskowska i M. Jaracz (red.), Studia linguistica in honorem Edvardi Breza (s. 37-54). Bydgoszcz: Wydawnictwo UKW.

Ortsnamenkonflikte in multiethnischen Gebieten Polens. W: N. Eller, S. Hackl i M. L'upták (red.), Namen und ihr Konfliktpotential im europäischen Kontext. Regensburger Symposium, 11.-13. April 2007. Regensburger Studien zur Namenforschung (t. 4, s. 229-238). Regensburg: Edition Vulpes.

[rec.] I. Kałużyńska, Chinese female namings. Past and present, Warszawa 2008, 410 s. Onomastica, 53, 216-218.

[rec.] G. Koss, Warennamen — Marken — Kunstnamen. Transposition und Kreation in der Wirtschaft. Ausgewählte Beiträge 1976-2006. Festschrift für Gerhard Koß zum 75. Geburtstag, red. K. Franz, A. Greule i S. Hackl. Regensburger Studien zur Namenforschung, Bd. 5, Regensburg 2008, 256 s., Onomastica, 53, 201-202.

[rec.] T. Wicherkiewicz, The Making of a Language. The Case of the Idiom of Wilamowice, Southern Poland, Berlin-Nowy Jork 2003, 539 s., Multilingua, 27(1-2), s. 196.

[rec.] Zunamen. Zeitschrift für Namenforschung/Surnames. Journal of Name Studies, red. S. Brendler, t. 1-2, Hamburg 2006-2007. Onomastica, 53, 239-240.

[spraw.] 23. Międzynarodowy Kongres Onomastyczny (Toronto, 17-22 sierpnia 2008). Onomastica, 53, 270-274.

[red., z K. Rymutem; autorka części haseł] Nazwy miejscowe Polski. Historia. Pochodzenie. Zmiany [Place Names of Poland. History. Origin. Changes] (t. VIII: O-Pn). Kraków: Instytut Języka Polskiego PAN.

Vornamen von polnischen Immigranten im Ruhrgebiet. W: W. Ahrens, S. Embleton i A. Lapierre (red.), Namen in Multi-Lingual, Multi-Cultural and Multi-Ethnic Contact. Proceedings of the 23rd International Congress of Onomastic Sciences, August 17-22, 2008, York University, Toronto, Canada (s. 254-266). Toronto: York University. 
Funkcje nazw własnych w poezji Zbigniewa Herberta (na przykładzie tomiku „Pan Cogito") [Functions of proper names in poetry of Zbigniew Herbert (on the example of „Pan Cogito”)]. W: R. Łobodzińska (red.), Nazwy własne a społeczeństwo [Proper Names and Society] (t. 2, s. 445-452). Łask: Leksem.

Instytut Języka Polskiego PAN i jego dyrektorzy [Institute of Polish Language and it's directors]. W: B. Czopek-Kopciuch i P. Żmigrodzki (red.), Język polski wczoraj, dziś, jutro... [Polish — Yesterday, Today, Tomorrow...] (s. 61-66). Kraków: Lexis.

[autorka części haseł] K. Rymut i J. Hoffman (red.). Lexikon der Familiennamen polnischer Herkunft im Ruhrgebiet (t. 2: M-Z). Kraków: Instytut Języka Polskiego PAN.

[red., z P. Żmigrodzkim] Język polski — wczoraj, dziś, jutro... [Polish — Yesterday, Today, Tomorrow...]. Kraków: Lexis.

[rec.] S. Brendler, Nomematik. Identitätstheoretische Grundlagen der Namenforschung (insbesondere der Namengeschichte, Namenlexikographie, Namengeographie, Namenstatistik und Namenstheorie), Hamburg 2008, 448 s. Onomastica, $54,321-323$.

[rec.] Namenarten und ihre Erforschung. Ein Lehrbuch für das Studium der Onomastic. Anlässlich des 70. Geburtstages von Karlheinz Hengst, red. A. Brendler i S. Brendler, Lehr- und Handbücher zur Onomastik, t. 1, Hamburg 2004, 1024 s. Onomastica, 54, 332-333.

[rec.] Onomastica Slavogermanica, XXV, red. E. Eichler, Stuttgart-Leipzig 2008, 429 s., Onomastica, 54, 349-350.

[rec.] H. Tiefenbach, Von Mimigernaford nach Reganespurg. Gesammelte Schriften zu altsächsischen und althochdeutschen Namen, red. A. Greule i J. Riecke. Regensburger Studien zur Namenforschung, t. 6, Regensburg 2009, 368 s., Onomastica, 54, 329-330.

[rec.] Zunamen. Zeitschrift für Namenforschung / Surnames. Journal of Name Studies, red. S. Brendler, t. 4/I, Hamburg 2009. Onomastica, 54, 342-343.

\section{1}

Geographical names deriving from saints' names (patrocinia) in Poland. Onomastica Uralica, 8, 227-245.

[z U. Bijak i A. Cieślikową] Maty stownik nazw polskich miast, państw Europy, ich stolic i mieszkańców [A Small Dictionary of the Names of Polish Cities, European Countries, Their Capitals and Inhabitants]. Warszawa: Oficyna Wydawnicza Rytm.

Polnische Familiennamen im Deutschen. Dargestellt am Beispiel der polnischen Familiennamen im Ruhrgebiet. W: K. Hengst i D. Krüger (red.), Familiennamen im Deutschen. Erforschung und Nachschlagewerke. Familiennamen aus 
fremden Sprachen im deutschen Sprachraum. Jürgen Udolph zum 65. Geburtstag zueeignet (t. 2, s. 189-202). Leipzig: Leipziger Universitätsverlag.

Prace Komisji Nazw Miejscowych i Obiektów Fizjograficznych przy MSWiA [Works of the Commission on Names of Localities and Physiographic Objects of the Ministry of Internal Affairs and Administration]. W: M. Gradziński, J. Partyka i J. Urban (red.), Materiały 45. Sympozjum Speleologicznego, Ojców 20-23.10.2011 $r$. [Materials of the $45^{\text {th }}$ Speleological Symposium, Ojców, 20-23 October 2011] (s. 54). Kraków: Sekcja Speleologiczna Polskiego Towarzystwa Przyrodników im. Kopernika.

Zachodnioeuropejskie poglądy na chrematonimię [Western European views on chrematonymy]. W: M. Biolik i J. Duma (red.), Chrematonimia jako fenomen wspótczesności [Chrematonymy as a Present-Day Phenomenon] (s. 125-132). Olsztyn: Wydawnictwo UWM.

Zmiany nazw miejscowości w świetle prac Komisji Nazw Miejscowości i Obiektów Fizjograficznych (na przykładzie województwa łódzkiego) [Changes of place names in the light of the works of the Commission on Names of Localities and Physiographic Objects (as exemplified by the names of the Łódź Voivodeship)]. W: M. Obrusznik-Partyka i L. Pacan-Bonarek (red.), Nie tylko o dydaktyce... Księga pamiatkowa ofiarowana Profesor Annie Grochulskiej [Not Only About Didactics... A Memorial Book Donated to Professor Anna Grochulska] (s. 73-80). Piotrków Trybunalski: Naukowe Wydawnictwo Piotrkowskie.

[rec.] Zunamen. Zeitschrift für Namenforschung / Surnames. Journal of Name Studies, red. S. Brendler, t. 5/I-II, Hamburg 2010, 217 s., Onomastica, 55, 249-250.

\section{2}

Baza mroz w polskich toponimach i antroponimach [The root mroz in Polish toponyms and anthroponyms]. W: I. Łuc i M. Pogłódek (red.), W komunikacyjnej przestrzeni nazw własnych i pospolitych. Ksiega jubileuszowa dedykowana Profesorowi Robertowi Mrózkowi [In the Communication Space of Proper and Common Names. Essays in Honour of Professor Robert Mrózek] (s. 131-142). Katowice: Wydawnictwo UŚ.

Prace Komisji Nazw Miejscowości i Obiektów Fizjograficznych przy MSWiA [Works of the Commission on Names of Localities and Physiographic Objects of the Ministry of Internal Affairs and Administration]. Archiwum Fotogrametrii, Kartografii i Teledetekcji, 23, 71-79.

\section{3}

Frekwencja i geografia imion najrzadziej nadawanych w Polsce w latach 1995-2010 [The frequency and geography of names most rarely given in Poland during the years 1995-2010]. Onomastica, 57, 71-93. 
Imiona nadawane w Warszawie w latach 1995-2010 [Names given in Warsaw during the years 1995-2010]. W: E. Dzięgiel i T. Korpysz (red.), Niejedno ma imię... Prace onomastyczne $i$ dialektologiczne dedykowane Profesor Ewie Wolnicz-Pawłowskiej [Onomastic and Dialectological Works Dedicated to Professor Ewa Wolnicz-Pawłowska] (s. 83-95). Warszawa: Wydawnictwo UKSW.

Names of companies in Poland. W: O. Felecan i A. Bugheşiu (red.), Onomastics in Contemporary Public Space (s. 120-130). Newcastle upon Tyne: Cambridge Scholars Publishing.

[red., z K. Rymutem; autorka części haseł] Nazwy miejscowe Polski. Historia. Pochodzenie. Zmiany [Place Names of Poland. History. Origin. Changes] (t. IX: Po-Q). Kraków: Instytut Języka Polskiego PAN.

[rec.] I. Bily, Potsdam bis München: Die Ausfahrten der A 9 - ihre Namen kurz erklärt. Das Namenbuch fürs Handschuhfach. Engelsdorfer Verlag, Leipzig 2012, 131 s., Onomastica, 57, 299-300.

[rec.] Lexicon der Vornamen, 6. völing neu bearbeitete Auflage von Rosa und Volker Kohlheim, Dudenverlag, Mannheim-Zürich 2013, 480 s., Onomastica, 57, 302-303.

[rec.] R. Šrámek, Beiträge zur allgemeinen Namentheorie, red. E. Hansack, Schriften zur diachronen Sprachwissenschaft, t. 16, Praesens Verlag, Wien 2007, 569 s., Onomastica, 57, 239-240.

[rec.] The Great Toponymic Divide. Reflections on the Definition and Usage of Endonyms and Exonyms, red. P. Woodman, Główny Urząd Geodezji i Kartografii, Warszawa 2012, 302 s. Onomastica, 57, 286-287.

\section{4}

Onomastyka przyszłości [Onomastics of the future]. Polonica, 34, 167-171.

Works of the Commission on Names of Localities and Physiographic Objects of the Ministry of Internal Affairs and Administration. W: J. Tort i Donada, M. Montagut i Montagut (red.), Els noms en la vida quotidiana. Actes del XXIV Congrés Internacional d'ICOS sobre Ciéncies Onomàstiques / Names in daily life. Proceedings of the XXIV ICOS International Congress of Onomastic Sciences, Barcelona, 5-9 September 2011 (s. 2501-2507). Barcelona: Generalitat de Catalunya.

\section{5}

[red., z K. Rymutem i U. Bijak; autorka części haseł] Nazwy miejscowe Polski. Historia. Pochodzenie. Zmiany [Place Names of Poland. History. Origin. Changes] (t. X: Ra-Re). Kraków: Instytut Języka Polskiego PAN.

[red., z K. Rymutem i U. Bijak; autorka części haseł] Nazwy miejscowe Polski. Historia. Pochodzenie. Zmiany [Place Names of Poland. History. Origin. Changes] (t. XI: Rę-Rs). Kraków: Instytut Języka Polskiego PAN. 
[red., z K. Rymutem i U. Bijak; autorka części haseł] Nazwy miejscowe Polski. Historia. Pochodzenie. Zmiany [Place Names of Poland. History. Origin. Changes] (t. XII: Ru-Rż). Kraków: Instytut Języka Polskiego PAN.

2016

[red., z K. Rymutem i U. Bijak; autorka części haseł] Nazwy miejscowe Polski. Historia. Pochodzenie. Zmiany [Place Names of Poland. History. Origin. Changes] (t. XIII: Sa-Si). Kraków: Instytut Języka Polskiego PAN.

Nick - nowa kategoria antroponimiczna? [Internet nickname - a new anthroponymic category?]. W: M. Kita i I. Loewe (red.), Język w internecie. Antologia [Language on the Internet. Anthology] (s. 123-127). Katowice: Wydawnictwo UŚ. [Przedruk za: K. Michalewski (red.), Współczesne odmiany języka narodowego [Contemporary Varieties of the National Language] (s. 106-111). Łódź: Wydawnictwo UŁ.

\section{7}

Imię Maria w polskiej ojkonimii [The personal name Maria in Polish oikonymy]. Onomastica, 61(2), 43-51.

[red., z K. Rymutem i U. Bijak; autorka części haseł] Nazwy miejscowe Polski. Historia. Pochodzenie. Zmiany [Place Names of Poland. History. Origin. Changes] (t. XIV: Sk-Sn). Kraków: Instytut Języka Polskiego PAN.

Wkład Kazimierza Rymuta do polskiej onomastyki [Kazimierz Rymut's contribution to Polish onomastics]. W: Z. Zaron i M. Grochowski (red.), Znaki Pamięci 2. Spuścizna językoznawców polskich drugiej połowy XX wieku [Signs of Remembrance 2. The Legacy of Polish Linguists of the Second Half of the $20^{\text {th }}$ Century] (s. 97-106). Warszawa: Wydawnictwo BEL Studio.

\section{8}

[z K. Skowronek, H. Górny, M. Magdą-Czekaj, E. Palinciuc-Dudek i E. Supranowicz] „Najczęstsze nazwiska w Polsce — współczesność i historia. Słownik elektroniczny”. Stan badań nad projektem [,,The most popular surnames in Poland present and past. E-dictionary". Progress report]. Onomastica, 62, 299-314.

[red., z U. Bijak; autorka części haseł] Nazwy miejscowe Polski. Historia. Pochodzenie. Zmiany [Place Names of Poland. History. Origin. Changes] (t. XV: So-Stą). Kraków: Instytut Języka Polskiego PAN.

O kilku ważnych rocznicach [About several important anniversaries]. W: U. Bijak, H. Górny i M. Magda-Czekaj (red.), Onomastyka — neohumanistyka - nauki społeczne [Onomastics — Neohumanistics — Social Sciences] (s. 11-14). Kraków: Instytut Języka Polskiego PAN. 
Portret onomastyczny Stefana Reczka [Onomastic portrait of Stefan Reczek]. Stowo. Studia językoznawcze, 9, 11-22.

Once more about the need to harmonize onomastic terminology. Annales Universitatis Mariae Curie-Skłodowska. Sectio FF. Philologiae, 37(1), 83-90.

Niemieckie nazwiska polskich językoznawców [German surnames of Polish linguists]. W: B. Grabka, R. Kucharzyk, A. Tyrpa (red.), Studia Dialektologiczne [Dialectological Studies] (t. 5, s. 25-40). Kraków: Instytut Języka Polskiego PAN.

Jeszcze o potrzebie ujednolicenia terminologii onomastycznej [Once more about the need to harmonize onomastic terminology]. W: A. Siwiec, I. Domaciuk-Czarny i M. Kojder (red.), Ze studiów nad nazwami własnymi. Terminologia - teoria i metodologia badań - zagadnienia nazwotwórstwa [Essays on Proper Names. Terminology — Theory and Methodology of Research — Issues of Naming] (s. 47-54). Lublin: Wydawnictwo UMCS. [Przedruk za: Annales Universitatis Mariae Curie-Skłodowska. Sectio FF. Philologiae, 37(1), 2019, 83-90].

[z U. Bijak] Toponyms of selected communes with minority languages in northeastern Poland (legal regulations and practice). Onomàstica. Anuari de la Societat d'Onomàstica, 6, 125-137.

Multiculturalism in Polish toponymy. W: O. Felecan i A. Bugheșiu (red.), Names and Naming. Multicultural Aspects (s. 331-343). London: Palgrave Macmillan (Springer Group). 